\title{
Toxicity of Film Production: Materializing the Light and Shadow
}

\author{
Longfei Chen ${ }^{1, *}$ \\ ${ }^{1}$ Department of Film and Media Studies, UCSB, Santa Barbara, California, 93106 \\ *Corresponding author. Email:longfei_chen@ucsb.edu
}

\begin{abstract}
In the age of digital media, film as a digital medium has been heavily studied. However, most studies are focusing on the cultural influences and artistic aspects of film. The aim of this review is to evaluate film's impact on the environment, labor, and society, which are rarely discussed together by scholars. Evidences reviewed in this paper have a variety of digital sources, range from blogs and online journals to movies and interviews. The evidences, collectively, implicate a corrupted nature of the production of popular cinema due to its reliance on capitalistic ideologies, suggesting the need for more efficient regulations on the film industry.
\end{abstract}

Keywords: film production, toxicity, environmental pollution, labor exploitation, capitalism

\section{INTRODUCTION}

The medium of film is often thought of as a potential transmitter of environmental and humanistic ideals. For decades, countless influential film workers have commented on the fact that human activities are more and more detrimental to the well-being of nature and disclosed some companies' inhuman disposal of their employees. The world famous, Oscar-winning actor Leonardo DiCaprio has once expressed his concerns on human beings' ignorance towards global warming and appealed for a sustainable environmental future in his The 11th Hour [6]; Ken Loach's Sorry We Missed You tells the story of a stressful deliveryman and sighs over the helplessness and despair of oppressed labors [12]. However, unknown to those who appreciate popular cinema for its positive contributions to the construction of an environmentally and socially utopian world, numerous studies have indicated that the productions of Hollywood films are actually doing quite the opposite. A 2006 UCLA study debunks the industry's heavy ecological footprint, revealing its formidable annual release of 15 million metric tons of $\mathrm{CO} 2$ in the US alone [1]. Moreover, the industry is also accused of labor exploitation by media theorists, suggesting its unfair treatment toward affiliated digital workers [2;3]. It's obvious now that the avant-garde approach can no longer suffice a comprehensive understanding of film production; instead of emphasizing film production as an expression of artistry and ideologies through visual effects, people should start to consider it as parallel to the production of commodities that bears heavily on capitalism. This essay studies film production's negative environmental impacts and exploitation of labor in the context of popular cinema, showing signs of commodification and toxicity in its nature. To review film production practices critically through both environmentalist and humanistic lenses helps understand their flaws and appeal for a more ecologically and socially friendly film industry.

\section{ENVIRONMENTAL HAZARDS OF FILM PRODUCTION}

Set productions are often seemed to be very transparent. Especially in the case of blockbusters, there are always scenes that need to be shot in heavily populated areas; for instance, Christopher Nolan's The Dark Knight Rises was also filmed primarily in the city of NY, and numerous scenes were set in public areas like the Wall Street [5]. However, despite the fact that set productions are usually open to public scrutinization, heavy pollutions are still produced behind the curtain. A fighting scene in The Dark Knight Rises between Batman and Bane was shot in the 5th avenue. To normal spectators, this might just be a crowd fighting of hundreds of costumed actors, and there is no sign of heavy pollution. Nevertheless, to make this scene even possible, there is an enormous 
amount of work that needs to be done beforehand, and the real pollution comes from the invisible parts of the visible. Nakamura has lamented in her essay Indigenous Circuits that people tend to visualize the technological progress as linear instead of working in circuits, thus overlooking the sources and noxious consequences of innovation

[11].

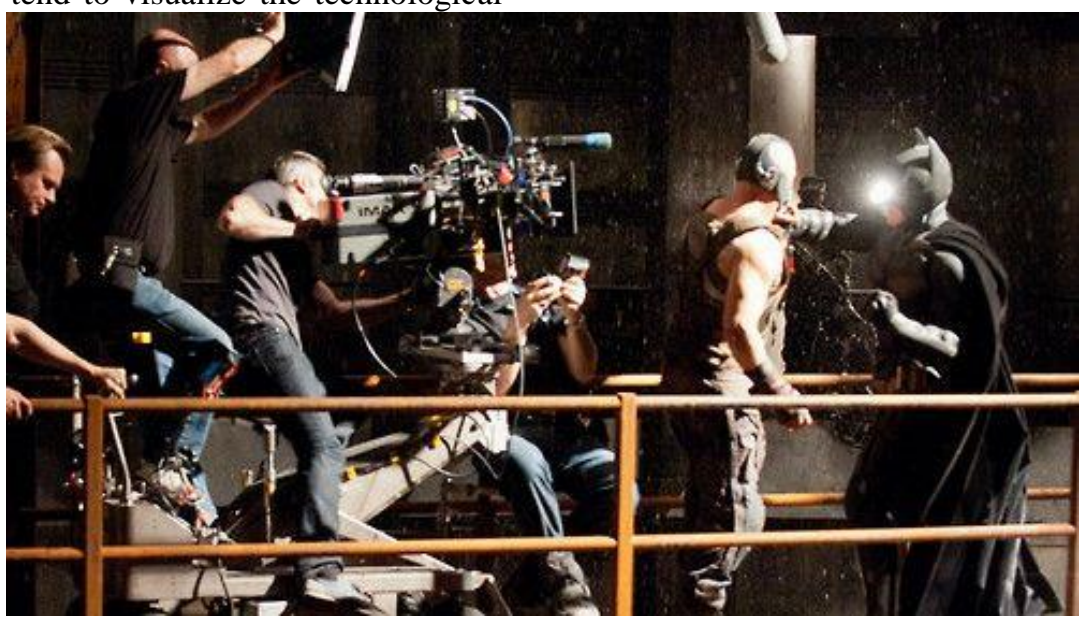

Figure 1: BTS of Dark Knight Rises

Toxicity is often concealed by people's lack of effort to discover the full picture of toxic human activities and stay on the surface level of comprehension. When people debate about the pros and cons of the new features of new Iphones, they are reading innovations as merely results of consumerism; they forget to regard the actual makers of these innovations: the nimble fingers of digital labors. Similarly, when people are having conversations on whether the 5th avenue fight scene is amazing or not, they disregard the prototyping and production of all the fancy customs and vehicles, the transportation of hundreds of people from set to set, the on-set consumption of bottled water and food, and the electricity that is required to run all the lighting equipment, voice recorders and digital cameras.

In the 2006 UCLA report, all of these prerequisites for a big-budget set are discussed in detail. Firstly, costume designers and production designers are often needed to put off their planning and budgeting of designing and production due to directors' and producers' delay of choice making, which leads to more waste and higher expense. Secondly, transportation is also costly and pollution-generating. Take LA for instance, transportation costs " $\$ 30000$ per day in Los Angeles for one particular show." In addition, "most trucks in the studio fleets run on diesel," while switching to vehicles using cleaner fuels usually won't fulfill the needs of the production. Lots of food and water are also wasted in set productions. According to a review of a line producer, "a lot of people grab water bottles, drink just a little, then leave the bottle with most of the water to be thrown away." Food and water leftovers are composed of both non-degradable and residual wastes that will leave huge burdens for recyclers to handle. Last but not least, despite the environmental drawbacks of diesel generators, they are commonly used due to the high energy consumption of the lighting required. Cameras and sound recorders are also operating with the support of lithium batteries, and these batteries are both very dangerous and very costly to recycle. In Crawford and Joler's words, film production "runs on the tears and breast milk of a volcano," and is connected to the essence of the planet [2].

It's haunting to even start thinking about the deeper layers of the material part of film production's toxicity. Production waste, transportation pollution, food and water waste, and excessive usage of electricity are invisible to most audiences but are at least realized by the producers. There are layers of extraction, from the mining of lithium to power the machines to the extracting of particles that were created 13.8 billion years ago to make the plastic lens covers, that are even ignored by the filmmakers themselves [8]. In other words, filmmakers are using the earth to the record the Earth while disrespecting the Earth at the same time.

\section{LABOR EXPLOITATION OF FILM PRODUCTION}

The negative effect of the film industry is not limited to environmental pollutions. It is also composed of several layers of labor exploitation. The industry advances with the advances of technology. As a result, it is taking part in the exploitation of the digital labors. There are now companies that are solely dedicated to the production of cinema cameras, such as RED, which is associated with labor exploitation that the industry should be wholly responsible for. Digital cameras, external camera monitors, camera stabilizers, and so many filming equipment are all made of chips and electric circuits. As camera equipment companies are 
fighting for their positions in the market with products with better qualities and cheaper prices, labors of chip manufacturing companies are hired with less and less income. In Nakamura's case study, the Fairchild company hired Navajo women to save production cost. The exploited workers need to finish extraordinarily difficult tasks despite their below-minimum wages. Chip manufacturing workers, outsourced or crowdsourced, are all working day and night to support this unfair circuit of production, while the filmmakers and moviegoers who benefit from them are unaware of their efforts or even their existence.

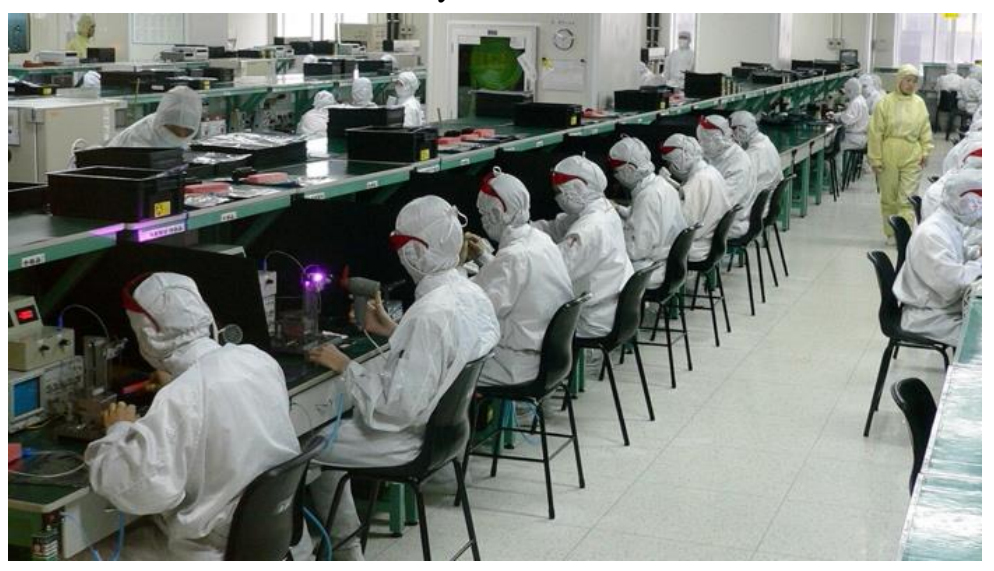

Figure 2: A Look Into a Chinese iPhone Factory

What's more, as more regulations and laws are issued in recent years to break the conglomerations in the film industry, film production companies are cut down greatly on their capitals. The result can be perfectly explained by a Chinese cyberspeak 'involution', which means vicious inner competitions among workers in the same industry or companies. This definition suits well to the context of creative labors in the film industry. Curtin observes in his 2016 study that the VFX business is representing a "quintessential 'race to the bottom';" companies are exploiting their own creative labors without hiring new ones to win the bidding wars [4]. The Big Six need to lower their expenses on production, so the cheapest VFX company to work with will be selected. Thus, the VFX companies are no longer profiting from a bigger team or more skillful employees; they profit through 'involution,' the constant squeezing of their already exhausted labors. Creative labors in the VFX business, as a result, need to withstand the consequences of the industry's 'involution' to keep their jobs.

\section{CINEMATIC ART AS COMMODITY}

Both the environmental pollution caused by set production and labor exploitation in the industry are justifying the fact that film can no longer be understood merely as the art of vision and the eye [13]. Modernist filmmakers negate the conventions of the popular cinema to pursue the purity of art, as Hollywood cinematic art has already become commodified [9]; investments in film industry are only going to the producers who can potentially benefit the investors with something in return, which, in most of the time, means money [7]. Sadly, cinema was born as a type of commodity, a vehicle of entertainment, when people paid money to watch the first films through the kinetoscope. This doesn't mean that films can't load artistry, as Polish Avant-garde and French New Wave filmmakers might argue against. Instead, film should and has been received by the general public as 'The Seventh Art,' but we should also admit the deep-rooted interconnections between popular cinema and capitalism. Being an epitome of capitalist ideologies, Hollywood film producers worship economic efficiency and economic returns. Their goal is to make more profitable movies faster and cheaper. It's not to say that investments in Hollywood blockbusters are low; on the contrary, the average cost of producing and distributing a Hollywood movie is already over US\$60 million by 2000, and the number keeps rising [10]. The true implication of 'faster and cheaper' productions is to save the time and costs that won't serve any purpose in the marketing of films, which include implementing environmental standards and paying fairly to the workers. As long as the productions are deemed to be green under public surveillance, the invisible pollution and exploitation will not harm the reception of the films.

\section{CONCLUSION}

With no doubt, people pay money on streaming platforms and go to movie theaters for the stories that films have to tell. Film's core as a medium is often ignored. It's very dangerous for society to not see the 'messages' of this medium itself. Among these 'messages', there are ones that imply hazardous results: despite being fairly transparent and envisioned by many as green, set productions are still afflicted by its hefty ecological footprint as a result of invisiblized detrimental factors; labors who contribute to the 
production are exploited, including the flexible labors who produced the equipment for filming and the individual creative labors whose talents are deemphasized for companies' economic interests. All in all, in the context of the globalization of capital practices and neoliberalism, film productions should no longer be deemed as solely artistic expressions of social messages; people should be more aware of the downsides of our mental pabulums, and the US government and regulatory institutions of the American cinema should step forward and issue laws that enforce environment-friendly practices and fair treatments of labors in the production of films.

\section{ACKNOWLEDGMENT}

I have to start by thanking my course mentors in UCSB, Nicole Strobel and Stephen Borunda. From providing me initial research aims to giving feedbacks of early drafts, they were so significant that this essay would never be finished without their help. I also need to appreciate Min Han for giving me revising ideas and helping me to finalize this project. Thank you.

\section{REFERENCES}

[1] Corbett, Charles, and Richard Turco. Sustainability in the Motion Picture Industry. Rep. Los Angeles: UCLA Institute of Environment, 2006. Print.

[2] Crawford, Kate, and Vladan Joler. "Anatomy of an Ai System." Virtual Creativity 9.1 (2019): 117-20. Print.

[3] Curtin, Michael, and John Vanderhoef. "A Vanishing Piece of the Pi." Television \& New Media 16.3 (2014): 219-39. Print.

[4] Curtin, Michael. "Regulating the Global Infrastructure of Film Labor Exploitation." Film Policy in a Globalised Cultural Economy (2018): 7-19. Print.

[5] The Dark Knight Rises. Dir. Christopher Nolan. Perf. Christian Bale and Michael Caine. Amazon. 2012. Web. 2021.

[6] The 11th Hour. Dir. Leila Conners Petersen and Nadia Conners. Prod. Leila Conners Petersen, Leonardo DiCaprio, Chuck Castleberry, and Brian Gerber. By Leila Conners Petersen, Nadia Conners, Leonardo DiCaprio, and Leonardo DiCaprio. Web.

[7] Hagener, Malte. Moving Forward, Looking Back: The European Avant-garde and the Invention of Film Culture, 1919-1939. Amsterdam: Amsterdam UP, 2011. Print.

[8] Haskins, Caroline. "AirPods Are a Tragedy." VICE. Web. 04 Aug. 2021.
[9] Kuc, Kamila. Visions of Avant-garde Film. Indiana UP, 2016. Print.

[10] Liu, Zhen. "Hollywood Movies as Commodity and Culture: A Historical Review." Cross-Cultural Communication 12.1 (2016): 12-15. Print.

[11] Nakamura, Lisa. "Indigenous Circuits: Navajo Women and the Racialization of Early Electronic Manufacture." American Quarterly 66.4 (2014): 919-41. Print.

[12] Sorry We Missed You. Dir. Ken Loach. Perf. Kris Hitchen and Debbie Honeywood. Amazon. 2020. Web. 2021.

[13] Wees, William C. Light Moving in Time: Studies in the Visual Aesthetics of Avant-garde Film. Berkeley (Calif.): U of California, 1992. Print. 